\title{
Four novel ARSA gene mutations with pathogenic impacts on metachromatic leukodystrophy: a bioinformatics approach to predict pathogenic mutations
}

\author{
This article was published in the following Dove Press journal: \\ Therapeutics and Clinical Risk Management \\ 16 June 2017 \\ Number of times this article has been viewed
}

\author{
Masoumeh Dehghan \\ Manshadi ${ }^{\prime}$ \\ Behnam Kamalidehghan ${ }^{2,3}$ \\ Omid Aryani' \\ Elham Khalili' \\ Sepideh Dadgar' \\ Mahdi Tondar ${ }^{4}$ \\ Fatemeh Ahmadipour ${ }^{5}$ \\ Goh Yong Meng6 \\ Massoud Houshmand ${ }^{1,3}$ \\ 'Department of Medical Genetics, \\ Special Medical Center, Tehran, Iran; \\ ${ }^{2}$ Medical Genetics Department, \\ School of Medicine, Shahid \\ Beheshti University of Medical \\ Sciences, Tehran, Iran; ${ }^{3}$ Department \\ of Medical Genetics, National \\ Institute for Genetic Engineering \\ and Biotechnology, Tehran, Iran; \\ ${ }^{4}$ Department of Biochemistry and \\ Molecular \& Cellular Biology, School \\ of Medicine, Georgetown University, \\ Washington, DC, USA; ${ }^{5}$ Department \\ of Pharmacy, Faculty of Medicine, \\ University of Malaya, Kuala Lumpur, \\ Malaysia; ${ }^{6}$ Department of Veterinary \\ Preclinical Sciences, Faculty of \\ Veterinary Medicine, Universiti Putra \\ Malaysia, Selangor, Malaysia
}

Correspondence: Massoud Houshmand Department of Medical Genetics,

National Institute of Genetic Engineering

and Biotechnology, Shahrak-e

Pajoohesh, km I5, Tehran - Karaj

Highway, Tehran, Iran

Tel +98 2l 44580390

Fax +98 2I 44580399

Email massoudh@nigeb.ac.ir

\begin{abstract}
Metachromatic leukodystrophy (MLD) disorder is a rare lysosomal storage disorder that leads to severe neurological symptoms and an early death. MLD occurs due to the deficiency of enzyme arylsulfatase A (ARSA) in leukocytes, and patients with MLD excrete sulfatide in their urine. In this study, the ARSA gene in 12 non-consanguineous MLD patients and 40 healthy individuals was examined using polymerase chain reaction sequencing. Furthermore, the structural and functional effects of new mutations on ARSA were analyzed using SIFT (sorting intolerant from tolerant), I-Mutant 2, and PolyPhen bioinformatics software. Here, 4 new pathogenic homozygous mutations c.585G $>$ T, c.661T $>$ A, c.849C $>$ G, and c.911A $>$ G were detected. The consequence of this study has extended the genotypic spectrum of MLD patients, paving way to a more effective method for carrier detection and genetic counseling.
\end{abstract}

Keywords: psychomotor regression, demyelinating, gait abnormality and impairment, metachromatic leukodystrophy (MLD), behavioral disturbances

\section{Introduction}

Metachromatic leukodystrophy (MLD) is a rare lysosomal storage disorder, caused by deficiency of the enzyme arylsulfatase A (ARSA, E.C. 3.1.6.1) with a frequency of approximately 1 per 40,000 worldwide. ${ }^{1}$ ARSA catalyzes initiative step of the metabolic pathway, sphingolipid 3'-o-sulfogalactosylceramide, known as sulfatide. Sulfatide is especially abundant in the myelin sheath of the nervous system. ${ }^{2}$ Mutations in the ARSA gene (Figure 1) (GenBank accession number NP_000478) could lead to a deficiency in ARSA activity, leading to accumulation of sulfatide, especially in the nervous system. ${ }^{3,4}$ This phenomenon causes a progressive demyelination that leads to different neurological symptoms including ataxia, an initially flaccid and later spastic paresis, optic atrophy, and dementia. ${ }^{5}$

To date, there is no effective treatment for MLD. However, bone marrow transplantation and stem cell therapy can be beneficial for patients with juvenile- and adult-onset forms in the early stages of the disease. In addition, gene and enzyme replacement therapies for the treatment of MLD have shown promising outcomes in mice models. ${ }^{6-11}$

ARSA deficiency is divided into 3 clinical subtypes: late-infantile (50\%-60\%), juvenile $(20 \%-30 \%)$, and adult (15\%-20\%). The disorder course may range from 3 to 10 years or more in the late-infantile type and up to 20 years in the juvenile and adult types. ${ }^{9}$ 


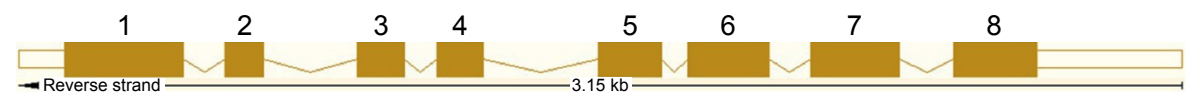

Figure I The ARSA gene maps to chromosome $22 q 13$ covers $3.2 \mathrm{~kb}$ of genomic DNA and includes 8 exons.

Typical magnetic resonance imaging (MRI) alterations in MLD have been explained in the literature. T2-weighted MRI (T2W MRI) of the brain in MLD patients typically indicates butterfly-shaped confluent white matter hyperintensities with early involvement of the corpus callosum. ${ }^{12}$ In addition, there is elevated white matter involvement, including U-fibers and cerebellar white matter, as well as cerebral atrophy with progression of the MLD disease. ${ }^{13-16}$ In this study, the ARSA gene was examined in individuals who met the proposed clinical criteria for MLD in order to identify the pathogenic impact of the associated mutations in MLD.

\section{Materials and methods}

\section{Patient collection and ethical statement}

In this study, 12 Iranian non-consanguineous MLD patients, with a mean age of 3.5 years, were diagnosed between January 2009 and November 2012. Clinical characteristics of MLD patients are summarized in Table 1. Blood samples from 12 MLD patients and 40 healthy individuals were obtained from the Special Medical Center (SMC), Tehran, Iran. Written informed consent for genetic study and molecular analysis and consent to publish results was obtained from the healthy controls, patients, and parents on behalf of their children. The clinical ethics committee of SMC specifically approved this study (Approval No ML-41-1224) in December 2012. The exclusion criteria for healthy individuals were any history of familial and sporadic cancers, hereditary and non-hereditary metabolic disorders, and nuclear and mitochondrial DNAassociated disorders.

\section{Enzymatic ARSA activity assay}

ARSA activity was determined in leukocytes using p-nitrocatechol sulfate as described previously by Molzer et al. ${ }^{17}$

\section{Neuroimaging (MRI) analysis}

T2-weighted spin-echo sequences of the brain were carried out using a Siemens Magnetom Avanto 1.5 Tesla MRI (Munich, Germany). Images were evaluated in a blind fashion by a neuroradiologist.

\section{DNA extraction and polymerase chain reaction (PCR)}

The genomic DNA was extracted from the blood samples of MLD patients by the QIAamp DNA Micro Kit (Qiagen \#56304). PCR primers ${ }^{18}$ for amplification of exons 1-8 of the ARSA gene are as indicated in Table 2. Briefly, PCR was carried out in final volumes of $25 \mu \mathrm{L}$, containing 100-200 ng of total genomic DNA, 10 pmol of forward and reverse primers, $2.5 \mathrm{mM}$ of $\mathrm{MgCl}_{2}, 200 \mathrm{mM}$ of each

Table I Clinical and biochemical features of 12 Iranian MLD patients

\begin{tabular}{llllllll}
\hline Patient no & $\begin{array}{l}\text { Age } \\
\text { (years) }\end{array}$ & Initial manifestation & $\begin{array}{l}\text { Age of onset } \\
\text { (years) }\end{array}$ & Neuropathy & Seizures & $\begin{array}{l}\text { Urine } \\
\text { sulfatides }\end{array}$ & $\begin{array}{l}\text { ARSA enzyme } \\
\text { activity (\%) }\end{array}$ \\
\hline PI & 8 & Gait abnormality & 5 & Demyelinating & + & $>20^{\dagger}$ & 3 \\
P2 & 5.5 & Behavioral disturbances & 4 & Demyelinating & - & $>20$ & 2.8 \\
P3 & 2.5 & Psychomotor regression & 2 & ND & - & $>20$ & 0 \\
P4 & 2 & Psychomotor regression & I & ND & + & $>20$ & 1.1 \\
P5 & 4 & Psychomotor regression & 2 & Demyelinating & - & $>20$ & 2.5 \\
P6 & 2 & Psychomotor regression & 1.5 & DTR: absent & - & $>20$ & 1.5 \\
P7 & 2 & Psychomotor regression & 1.5 & DTR: absent & - & $>20$ & 1.2 \\
P8 & 2.5 & Psychomotor regression & I & ND & - & $>20$ & 2 \\
P9 & 6 & Gait impairment & 4.5 & Demyelinating & - & $>20$ & 2.8 \\
PI0 & 6 & Behavioral & 4.5 & Demyelinating & - & $>20$ & 4 \\
PII & 3 & Gait & 2.5 & Demyelinating & - & $>20$ & 2.5 \\
PI2 & 4 & Psychomotor regression & 3 & ND & - & $>20$ & 2.8 \\
\hline
\end{tabular}

Note: ${ }^{\dagger}$ Times higher compared to normal.

Abbreviations: MLD, metachromatic leukodystrophy; ND, not determined; DTR, deep tendon reflexes. 
Table 2 PCR primers for amplification of ARSA gene in MLD patients

\begin{tabular}{|c|c|c|c|c|}
\hline Primers & Exon & Primer sequence $\left(5^{\prime}-3^{\prime}\right)$ & $\begin{array}{l}\text { Amplicon } \\
\text { size (bp) }\end{array}$ & $\mathrm{TM}\left({ }^{\circ} \mathrm{C}\right)$ \\
\hline \multirow[t]{2}{*}{ I } & $\mathrm{I}$ & F: TCGGGGAGTATTTGGGTC & 405 & 57 \\
\hline & & R: GCAATCCATTGGGAGGAAAG & & \\
\hline \multirow[t]{2}{*}{2} & $1 *-2$ & F: TTGCCCGTCCGCCCAACATCGTG & 737 & 68 \\
\hline & & R: CCCTGGTCACAGCCACCGTCGCAAG & & \\
\hline \multirow[t]{2}{*}{3} & $2 *-4$ & F: GATTTCTAGGCATCCCGTACTC & 706 & 62 \\
\hline & & R: CCCTCACCCACTATGTTCTTG & & \\
\hline \multirow[t]{2}{*}{4} & $5-7 *$ & F: GCCAAGAACATAGTGGGTGAGG & 860 & 62 \\
\hline & & R: GGTAGAAGAAGAGAGACTGCCGAG & & \\
\hline \multirow[t]{2}{*}{5} & $7-8$ & F: GCAAGAAGCGGTGCACGTCC & 916 & 63 \\
\hline & & R: CCACGACACCAGGGTTCAAATCC & & \\
\hline
\end{tabular}

Note: *Due to the large size of exons I, 2, and 7, they are divided into 2 overlapping fragments.

Abbreviations: TM, temperature; PCR, polymerase chain reaction; MLD, metachromatic leukodystrophy; F, forward; R, reverse.

deoxyribonucleoside triphosphates (dNTP), and $1 \mathrm{U}$ of super Taq DNA polymerase (Roche Diagnostics, Mannheim, Germany). The PCR mixture was cycled for 35 times at $95^{\circ} \mathrm{C}$ for 1 minute; annealing temperature was based on temperature (TM) $\left({ }^{\circ} \mathrm{C}\right.$ ) of forward and reverse primers (Table 2$)$. The PCR products were examined on $2 \%$ agarose gel electrophoresis (Figure 2) in $0.5 \times$ Tris-borate-EDTA (TBE) buffer at $110 \mathrm{~V}$ for 50 minutes, and then stained with $0.002 \mathrm{mg} / \mathrm{mL} \mathrm{EtBr}$ solution and visualized using ultraviolet light.

\section{DNA sequencing and bioinformatics analysis}

The PCR products were sequenced by forward or reverse primers on an ABI 3700 sequencer (Kosar Company, Tehran, Iran) and the results were compared using Finch TV program and were then analyzed on the NCBI website (http://blast. ncbi.nlm.nih.gov/Blast.cgi). Moreover, the target sequence of patient was compared with normal reference sequence and ARSA gene mutations in exons and the splicing sites of the introns were identified. The functional and structural impacts

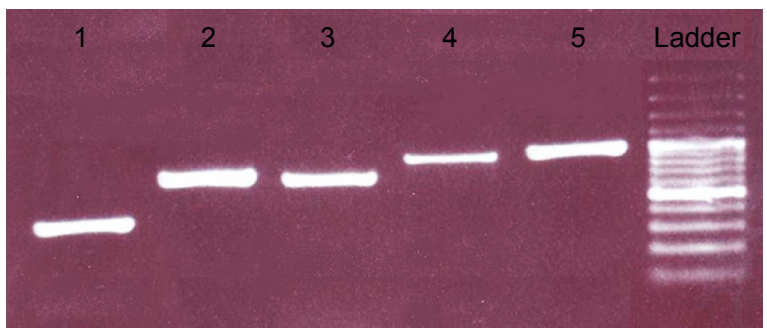

Figure 2 Agarose gel electrophoresis of PCR product. The presence of PCR products was confirmed by analyzing the products on a $2 \%$ agarose gel. From left: lane 1: exon I (405 bp), lane 2: exon I-2 (737 bp), lane 3: exon 2*-4 (706 bp), lane 4: exon 5-7* (860 bp), lane 5: exon 7-8 (916 bp), lane 6: DNA ladder (Thermo Scientific Gene Ruler 100 bp \#SM0241/2/3).

Abbreviation: $\mathrm{PCR}$, polymerase chain reaction. of identified novel mutations in ARSA gene were assessed using in silico prediction algorithms including SIFT, ${ }^{19}$ PolyPhen-2, ${ }^{20}$ and I-Mutant 2.0 (http://folding.biofold.org/ i-mutant/i-mutant2.0.html).

\section{Statistical analysis}

The chi-square test was used with Statistical Package for the Social Sciences (version 13) to examine the association between patient and healthy control samples, whereas $P$-value $<0.05$ was considered statistically significant.

\section{Results}

At T2W MRI, MLD patients demonstrated symmetric confluent areas of high signal intensity in the periventricular white matter (Figure 3: arrows in A-C) with sparing of the subcortical U-fibers (Figure 3: arrows in A). No enhancement is evident in computed tomography or MRI. The tigroid (Figure 3: arrows in D) and leopard skin (Figure 3: arrows in $\mathrm{E}$ and $\mathrm{F}$ ) patterns of demyelination, suggesting sparing of the perivascular white matter, are identified in the periventricular white matter and centrum semiovale. The corpus callosum, corticospinal, and internal capsule tracts are also frequently involved. The cerebellar white matter may appear hyperintense at T2W MRI. In the later step of MLD, corticosubcortical atrophy is often ascertained, particularly after involvement of the subcortical white matter.

Eight exons of the ARSA gene were examined in 12 patients with MLD symptoms. The c.100G $>$ A homozygous mutation in exon 1, c.661T $>$ A homozygous mutation in exon 3, c.739G $>$ A homozygous mutation in exon 4 , c. $827 \mathrm{C}>\mathrm{T}$ homozygous mutation in exon 4 , c.911A $>\mathrm{G}$ homozygous mutation in exon 5, c. $931 \mathrm{G}>\mathrm{A}$ homozygous mutation in exon 5 , c. $849 \mathrm{C}>\mathrm{G}$ homozygous mutation in 


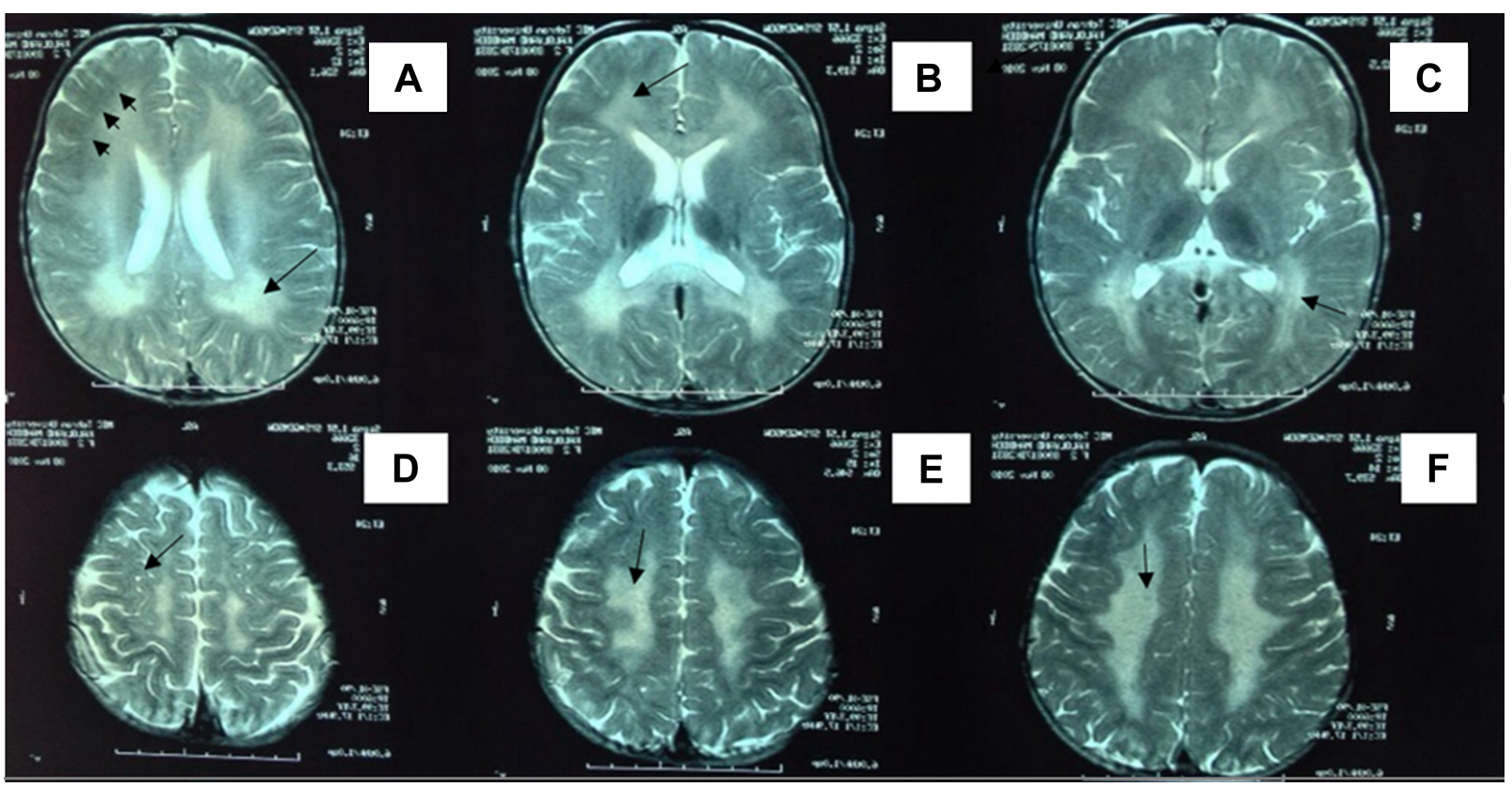

Figure 3 Axial T2-weighted brain MRI from patient P9.

Notes: The area with arrows represents of high signal intensity in the periventricular white matter (A-C) with sparing of the subcortical U-fibers (arrows), the tigroid (D) and leopard skin patterns of demyelination ( $\mathbf{E}$ and $\mathbf{F}$ ).

Abbreviations: MRI, magnetic resonance imaging; P9, patient 9

exon $4, A>G 96$ relative to termination codon homozygous mutation, W195C homozygous mutation in exon 3 , and c. $978+1 \mathrm{G}>\mathrm{A}$ homozygous mutation in intron 5 were detected as presented in Table 3. The 4 new mutations c. $585 \mathrm{G}>\mathrm{T}$, c. $661 \mathrm{~T}>\mathrm{A}$, c. $849 \mathrm{C}>\mathrm{G}$, and c. $911 \mathrm{~A}>\mathrm{G}$ were significantly $(P<0.05)$ identified in 4 patients (Table 4 and Figure 4A-D). The possible structural and functional effects of identified new mutations in ARSA were examined using the bioinformatics SIFT, PolyPhen, and I-Mutant 2.0 software. Here, SIFT outcomes showed that W195C, F221I, D283E, and K340R mutations were determined as deleterious with scores of $-0.734,-5.852,-3.908$, and -2.931 , respectively. I-Mutant analysis, based on the free energy change value (sign of DDG), demonstrated that p.W195C, p.F221I, p.D283E, and p.K340R mutations decreased protein stability. According to the PolyPhen score, the c. $585 \mathrm{G}>\mathrm{T}$, c. $661 \mathrm{~T}>\mathrm{A}$, c. $849 \mathrm{C}>\mathrm{G}$, and c. $911 \mathrm{~A}>\mathrm{G}$ mutations were determined as probably damaging the protein structure and function with scores of 0.994, 1.000, 1.000 and 1.000, respectively (Table 4).

Table 3 Mutations in the ARSA gene in Iranian MLD patients

\begin{tabular}{|c|c|c|c|c|c|}
\hline $\begin{array}{l}\text { Nucleotide } \\
\text { change }\end{array}$ & $\begin{array}{l}\text { Amino acid } \\
\text { change }\end{array}$ & Location & $\begin{array}{l}\text { Mutation } \\
\text { type }\end{array}$ & Status & References \\
\hline c. $100 G>A$ & p.G34S & Exon I & Missense & Homo $(I)^{*}$ & 21 \\
\hline c.585G $>\mathrm{T}$ & p.WI95C & Exon 3 & Missense & Homo (I) & Not reported \\
\hline c.66IT $>A$ & p.F22 I I & Exon 3 & Missense & Homo (I) & Not reported \\
\hline c. $736 \mathrm{C}>\mathrm{T}$ & p.R246C & Exon 4 & Missense & Homo (I) & 22 \\
\hline c.739G $>A$ & p.G247R & Exon 4 & Missense & Homo (I) & 23 \\
\hline c. $827 \mathrm{C}>\mathrm{T}$ & p.T276M & Exon 4 & Missense & Homo (I) & 24 \\
\hline c. $849 C>G$ & p.D283E & Exon 4 & Missense & Homo (I) & Not reported \\
\hline $\mathbf{c . 9}|| \mathbf{A}>\mathbf{G}$ & p.K304R & Exon 5 & Missense & Homo (I) & Not reported \\
\hline c. $931 \mathrm{IG}>\mathrm{A}$ & p.G3IIS & Exon 5 & Missense & Homo (2) & 25 \\
\hline $\mathrm{G}>\mathrm{A}$ & c. $978+I G>A$ & - & Splicing & Homo (I) & 27 \\
\hline$A>G$ & $\begin{array}{l}\mathrm{A}>\mathrm{G} 96 \text { relative to } \\
\text { termination codon }\end{array}$ & - & Regulatory & Homo (I) & 26 \\
\hline
\end{tabular}

Notes: *The number in parentheses in the status column shows the number of patients; new mutations are shown in bold. Abbreviation: MLD, metachromatic leukodystrophy. 
Table 4 Statistical and bioinformatics analysis of 4 novel pathogenic mutations

\begin{tabular}{|c|c|c|c|c|c|c|c|}
\hline \multirow[t]{3}{*}{ Patient no } & \multirow{3}{*}{$\begin{array}{l}\text { Novel } \\
\text { mutations }\end{array}$} & \multicolumn{3}{|c|}{ Statistical analysis } & \multicolumn{3}{|c|}{ Bioinformatics analysis } \\
\hline & & \multirow[t]{2}{*}{$P$-value } & \multicolumn{2}{|l|}{ PolyPhen 2} & \multicolumn{2}{|l|}{ SIFT } & \multirow{2}{*}{$\begin{array}{l}\text { I-Mutant } 2.0 \\
\text { Prediction (DDG) }\end{array}$} \\
\hline & & & Prediction & Score & Prediction & Score & \\
\hline $\mathrm{PI} 2$ & WI95C & $<0.05$ & Probably damaging & 0.994 & Deleterious & -0.734 & Decrease stability \\
\hline P2 & F22II & $<0.05$ & Probably damaging & 1 & Deleterious & -5.852 & Decrease stability \\
\hline P8 & D283E & $<0.05$ & Probably damaging & 1 & Deleterious & -3.908 & Decrease stability \\
\hline P6 & K304R & $<0.05$ & Probably damaging & I & Deleterious & -2.931 & Decrease stability \\
\hline
\end{tabular}

Notes: Novel pathogenic mutations were examined using 3 computational methods to assess the structural and functional impacts of novel amino acid changes: PolyPhen 2 (benign or damaging), SIFT (tolerated or deleterious), and I-Mutant 2.0 (increase or decrease stability). PolyPhen prediction score: benign ( $\leq 0.5)$ and probably damaging $(0.5<$ ). SIFT prediction score: tolerated $(\geq 0.05)$ and deleterious $(\leq 0.05)$. I-Mutant 2.0 prediction: Free energy change value (DDG): decreasing or increasing protein stability.

Abbreviations: SIFT, sorting intolerant from tolerant; DDG, the predicted free energy change value.

\section{Discussion}

In this study, 4 novel pathogenic mutations including c.585G $>\mathrm{T}$, c.661T $>\mathrm{A}$, c. $849 \mathrm{C}>\mathrm{G}$, and c.911A $>\mathrm{G}$ in the $A R S A$ gene were identified among 12 unrelated Iranian MLD patients. The previous reported mutations including the c.100G $>$ A mutation in patient $1(\mathrm{P} 1)$, c.736C $>$ T mutation in $\mathrm{P} 3, \mathrm{c} .739 \mathrm{G}>\mathrm{A}$ mutation in $\mathrm{P} 4$, c.827C $>\mathrm{T}$ mutation in $\mathrm{P} 5$, c.931G $>\mathrm{A}$ mutation in $\mathrm{P} 7$ and $\mathrm{P} 9, \mathrm{~A}>\mathrm{G} 96$ relative to the termination codon in $\mathrm{P} 15$, and c. $978+1 \mathrm{G}>\mathrm{A}$ mutation in $\mathrm{P} 11$ that were reported by Gort et al, ${ }^{21}$ Gieselmann et al, ${ }^{22}$ Hasegawa et al, ${ }^{23}$ Harvey et al, ${ }^{24}$ Kreysing et al, ${ }^{25}$ Gieselmann et al, ${ }^{26}$ and Eng et al, ${ }^{27}$ respectively.

Hence, additional research is required to affirm the biological role of these pathogenic mutations and confirm the in silico bioinformatics findings that have shown possible effects on protein structure and/or function in the absence of the ARSA enzyme.
The $A R S A$ gene has 8 exons, which are located on chromosome 22 (22q13.33). ${ }^{25}$ At present, more than 150 mutations were identified in the $A R S A$ gene according to the Human Gene Mutation Database (http://www.hgmd.cf.ac.uk/ ac/gene.php?gene=ARSA) (Figure 5).

MLD is a heterogeneous disease with 3 frequent defective alleles including a missense mutation that leads to a Ile179Ser substitution, a splice donor-site mutation at the exon 2 /intron 2 border, and a missense mutation that causes a Pro246Leu substitution, which account for $12 \%, 25 \%$ (among European patients), and 25\% of all defective alleles, respectively. ${ }^{28,29}$ Other mutant alleles were reported in only a few or single patients. ${ }^{30}$

\section{Conclusion}

The result of this research has broadened the genotypic spectrum of Iranian patients with MLD, paving way to a more
A

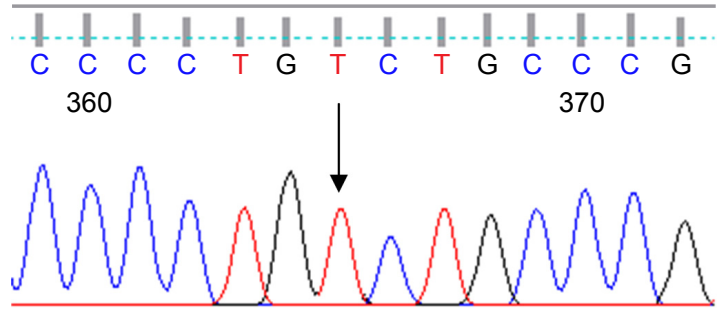

C

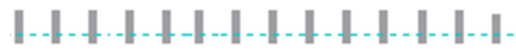

G C A G A G A A T G G G T A

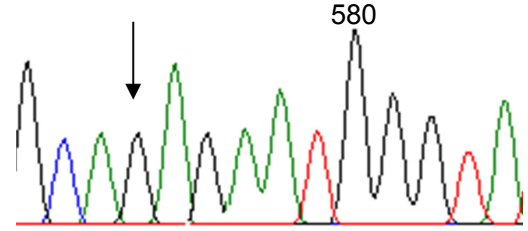

B

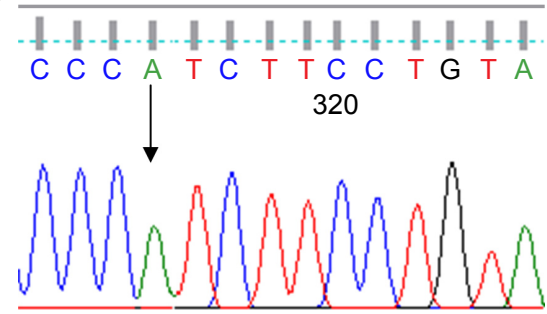

D

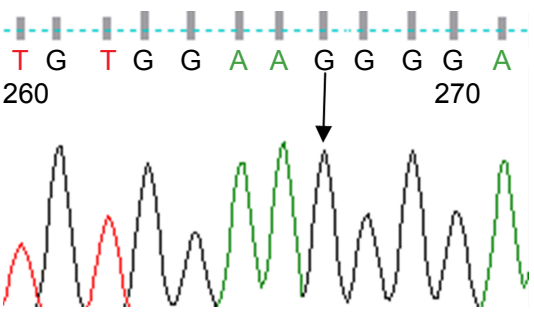

Figure 4 DNA sequencing result of the ARSA gene. (A) Sequence with a new G>T homo WI95C mutation (patient I2). (B) Sequence with a new T $>$ A homo F22II mutation (patient 2). (C) Sequence with a new C>G homo D283E mutation (patient 8). (D) Sequence with a new $A>G$ homo K304R mutation (patient 6). 


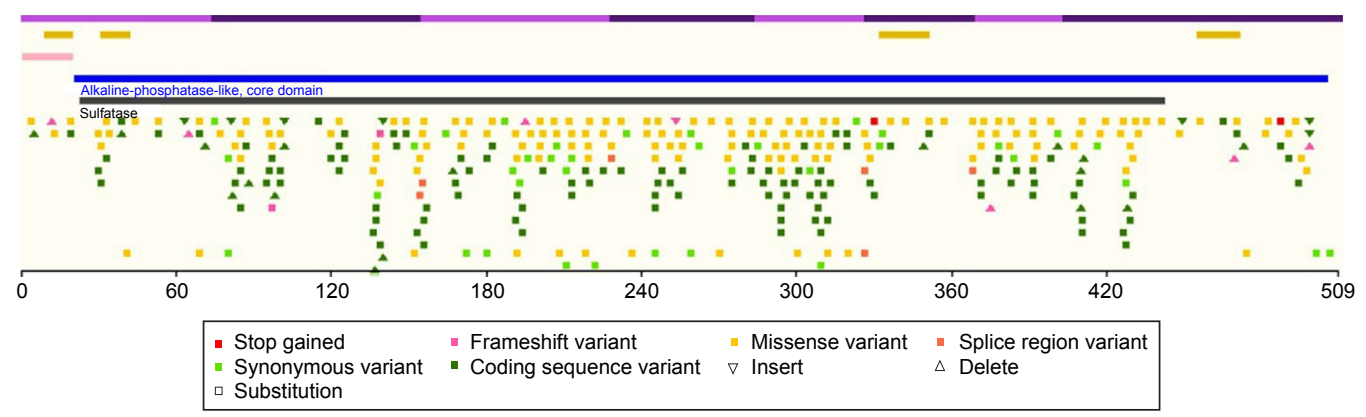

Figure 5 Mutations identified in the ARSA gene. (http://www.hgmd.cf.ac.uk/ac/gene.php? gene=ARSA).

Note: Reproduced from HGMD ${ }^{\circledR}$ [database on the Internet]. Cardiff, UK: Cardiff University. Available from: http://www.hgmd.cf.ac.uk/ac/gene.php?.gene=ARSA. Accessed April 4, 2017.31

effective method for career detection, genetic diagnosis, and counseling of Iranian patients with MLD disorder.

\section{Acknowledgments}

The authors of this study would like to appreciate all Iranian patients with MLD disorder from the Medical Genetics Department of the Special Medical Center, Tehran, Iran, for blood donation. The authors would like to express their utmost gratitude to SMC for providing financial support (MLD-6102) to conduct this study. Additionally, the funders of this study had no role in study design, data collection and analysis, decision to publish, or manuscript preparation.

\section{Author contributions}

$\mathrm{MH}$ conceived and designed the experiments. OA, EK, and SD performed the experiments and contributed to reagents/ materials/analysis tools. FA, GYM, and MT analyzed the data. BK wrote the manuscript, contributed to the discussion, and reviewed the manuscript. All the authors read and approved the final manuscript. All authors contributed toward data analysis, drafting and revising the paper and agree to be accountable for all aspects of the work.

\section{Disclosure}

The authors report no conflicts of interest in this work.

\section{References}

1. Gustavson KH, Hagberg B. The incidence and genetics of metachromatic leucodystrophy in northern Sweden. Acta Paediatr Scand. 1971; 60(5):585-590.

2. Gieselmann V, Franken S, Klein D, et al. Metachromatic leukodystrophy: consequences of sulphatide accumulation. Acta Paediatr Suppl. 2003;92(443):74-79; discussion 45.

3. van Rappard DF, Boelens JJ, Wolf NI. Metachromatic leukodystrophy: disease spectrum and approaches for treatment. Best Pract Res Clin Endocrinol Metab. 2015;29(2):261-273.

4. Gieselmann V, Krägeloh-Mann I. Metachromatic leukodystrophy - an update. Neuropediatrics. 2010;41(1):1-6.

5. Costello DJ, Eichler AF, Eichler FS. Leukodystrophies: classification, diagnosis, and treatment. Neurologist. 2009;15(6):319-328.
6. Batzios SP, Zafeiriou DI. Developing treatment options for metachromatic leukodystrophy. Mol Genet Metab. 2012;105(1):56-63.

7. Solders M, Martin DA, Andersson C, et al. Hematopoietic SCT: a useful treatment for late metachromatic leukodystrophy. Bone Marrow Transplant. 2014;49(8):1046-1051.

8. van Egmond ME, Pouwels PJ, Boelens JJ, et al. Improvement of white matter changes on neuroimaging modalities after stem cell transplant in metachromatic leukodystrophy. JAMA Neurol. 2013;70(6):779-782.

9. Wang RY, Bodamer OA, Watson MS, Wilcox WR; ACMG Work Group on Diagnostic Confirmation of Lysosomal Storage Diseases. Lysosomal storage diseases: diagnostic confirmation and management of presymptomatic individuals. Genet Med. 2011;13(5):457-484.

10. Biffi A, Naldini L. Novel candidate disease for gene therapy: metachromatic leukodystrophy. Expert Opin Biol Ther. 2007;7(8):1193-1205.

11. Sevin C, Aubourg P, Cartier N. Enzyme, cell and gene-based therapies for metachromatic leukodystrophy. J Inherit Metab Dis. 2007;30(2): 175-183.

12. Cheon JE, Kim IO, Hwang YS, et al. Leukodystrophy in children: a pictorial review of MR imaging features. Radiographics. 2002; 22(3):461-476.

13. Van der Knaap MS, Pouwels PJW. Magnetic resonance spectroscopy: basic principles and application in white matter disorders. In: van der Knaap MS, Valk J, editors. Magnetic resonance of myelination and myelin disorders. Berlin:Springer; 2005: 859-880.

14. Faerber EN, Melvin J, Smergel EM. MRI appearances of metachromatic leukodystrophy. Pediatr Radiol. 1999;29(9):669-672.

15. Kim TS, Kim IO, Kim WS, et al. MR of childhood metachromatic leukodystrophy. AJNR Am J Neuroradiol. 1997;18(4):733-738.

16. Eichler F, Grodd W, Grant E, et al. Metachromatic leukodystrophy: a scoring system for brain MR imaging observations. AJNR Am J Neuroradiol. 2009;30(10):1893-1897.

17. Molzer B, Sundt-Heller R, Kainz-Korschinsky M, Zobel M. Elevated sulfatide excretion in heterozygotes of metachromatic leukodystrophy: dependence on reduction of arylsulfatase A activity. Am J Med Genet. 1992;44(4):523-526.

18. Wang J, Zhang W, Pan H, et al. ARSA gene mutations in five Chinese metachromatic leukodystrophy patients. Pediatr Neurol. 2007;36(6): 397-401.

19. Kumar P, Henikoff S, Ng PC. Predicting the effects of coding nonsynonymous variants on protein function using the SIFT algorithm. Nat Protoc. 2009;4(7):1073-1081.

20. Adzhubei IA, Schmidt S, Peshkin L, et al. A method and server for predicting damaging missense mutations. Nat Methods. 2010;7(4): 248-249.

21. Gort L, Coll MJ, Chabás A. Identification of 12 novel mutations and two new polymorphisms in the arylsulfatase A gene: haplotype and genotype-phenotype correlation studies in Spanish metachromatic leukodystrophy patients. Hum Mutat. 1999;14(3):240-248.

22. Gieselmann V, Zlotogora J, Harris A, Wenger DA, Morris CP. Molecular genetics of metachromatic leukodystrophy. Hum Mutat. 1994;4(4): 233-242. 
23. Hasegawa Y, Kawame H, Eto Y. Mutations in the arylsulfatase A gene of Japanese patients with metachromatic leukodystrophy. DNA Cell Biol. 1993;12(6):493-498.

24. Harvey JS, Nelson PV, Carey WF, Robertson EF, Morris CP. An arylsulfatase A (ARSA) missense mutation (T274M) causing late-infantile metachromatic leukodystrophy. Hum Mutat. 1993;2(4): 261-267.

25. Kreysing J, von Figura K, Gieselmann V. Structure of the arylsulfatase A gene. Eur J Biochem. 1990;191(3):627-631.

26. Gieselmann V, Polten A, Kreysing J, von Figura K. Arylsulfatase A pseudodeficiency: loss of a polyadenylation signal and N-glycosylation site. Proc Natl Acad Sci US A. 1989;86(23):9436-9440.

27. Eng B, Nakamura LN, O'Reilly N, et al. Identification of nine novel arylsulfatase a (ARSA) gene mutations in patients with metachromatic leukodystrophy (MLD). Hum Mutat. 2003;22(5):418-419.
28. Polten A, Fluharty AL, Fluharty CB, Kappler J, von Figura K, Gieselmann V. Molecular basis of different forms of metachromatic leukodystrophy. N Engl J Med. 1991;324(1):18-22.

29. Berger J, Löschl B, Bernheimer H, et al. Occurrence, distribution, and phenotype of arylsulfatase A mutations in patients with metachromatic leukodystrophy. Am J Med Genet. 1997;69(3):335-340.

30. Schestag F, Yaghootfam A, Habetha M, et al. The functional consequences of mis-sense mutations affecting an intra-molecular salt bridge in arylsulphatase A. Biochem J. 2002;367(Pt 2):499-504.

31. $\mathrm{HGMD}^{\circledR}$ [database on the Internet]. Cardiff, UK: Cardiff University. Available from: http://www.hgmd.cf.ac.uk/ac/gene.php?gene=ARSA Accessed April 4, 2017.

\section{Publish your work in this journal}

Therapeutics and Clinical Risk Management is an international, peerreviewed journal of clinical therapeutics and risk management, focusing on concise rapid reporting of clinical studies in all therapeutic areas outcomes, safety, and programs for the effective, safe, and sustained use of medicines. This journal is indexed on PubMed Central, CAS,
EMBase, Scopus and the Elsevier Bibliographic databases. The manuscript management system is completely online and includes a very quick and fair peer-review system, which is all easy to use. Visit http://www.dovepress.com/testimonials.php to read real quotes from published authors.

Submit your manuscript here: http://www.dovepress.com/therapeutics-and-clinical-risk-management-journal 